\title{
The role of oral language skills in reading and listening comprehension of text: a comparison of monolingual (L1) and bilingual (L2) speakers of English language
}

\author{
Selma Babayiğit \\ Department of Psychology, University of the West of England, Bristol, UK
}

\begin{abstract}
The study examined the role of oral language skills in reading comprehension and listening comprehension levels of 125 monolingual (L1) and bilingual (L2) English-speaking learners $(M=121.5$ months, $S D=4.65)$ in England. All testing was conducted in English. The L1 learners outperformed their L2 peers on the measures of oral language and text comprehension, but the two groups performed at comparable levels on word-reading accuracy and speed. Oral language, indexed by vocabulary and morphosyntactic skills, emerged as the most powerful unique predictor of both reading and listening comprehension levels. Although there was a tendency of oral language to be more strongly related to L2 reading comprehension, its relationship with listening comprehension was comparable across the two language groups. Finally, individual differences in oral language skills emerged as the primary factor that explained the language group differences in text comprehension levels. Educational implications of these findings were discussed.
\end{abstract}

The number of primary school children who speak English as a second language in England is increasing by about $1 \%$ each year and according to these estimates within about 10 years, one-quarter of all primary school pupils will be non-native speakers of English (SFR, 2010). Similar rapidly changing demographic trends have been reported in many other countries, such as the United States and Canada (August, 2008; Lipka, Siegel \& Vukovic, 2005), prompting the calls for more nuanced investigations to address the current gaps in our understanding of the language and literacy development of this rapidly growing population of learners (August \& Shanahan, 2008; Goldenberg, Reese \& Rezaei, 2011).

There is now a substantial body of corroborating evidence suggesting that wordrecognition skills of bilingual (L2) ${ }^{1}$ learners develop fast and they tend to perform at comparable levels with their monolingual (L1) peers after a few years of exposure to formal reading instruction in their second language (for a review, see Lesaux, Geva, Koda, Siegel 
\& Shanahan, 2006). It is the development of reading comprehension skills of L2 learners which seems to be an issue. For instance, several studies on English-speaking L2 learners have found that despite adequate word-recognition skills, L2 learners tend to underperform on the measures of English reading comprehension. Limited English oral language proficiency, such as vocabulary knowledge, has been proposed to be one possible reason contributing to lower L2 performance on comprehension measures (for reviews, see Geva, 2000; Lesaux et al., 2006). However, these findings are not entirely unequivocal (e.g., see Lipka et al., 2005; Thomas \& Collier, 2002) and given the heterogeneity of L2 learners, there is the need for further research to examine L2 oral language and literacy development.

At present, with the exception of a notable few studies (e.g., Burgoyne, Kelly, Whiteley \& Spooner, 2009; Burgoyne, Whiteley \& Hutchinson, 2010; Frederickson \& Frith, 1998; Hutchinson, Whiteley, Smith \& Connors, 2003; Stuart, 2004), there is very limited research on English-speaking L2 learners in England. So far, all these studies have reported a significant L2 disadvantage in English oral language and text comprehension skills. With this study, the primary aim was to pursue these findings further and examine in more detail the relative role of oral language skills in reading and listening comprehension levels of L1 and L2 learners in England.

\section{Role of oral language in text comprehension}

Reading comprehension involves deciphering written text into spoken language. The latter, in turn, forms the primary medium through which mental representations of the meaning of the text are formed. This idea has been encapsulated by the well-known simple view of reading framework (Gough \& Tunmer, 1986; Hoover \& Gough, 1990). According to the simple view of reading, accurate word recognition and linguistic comprehension are central for reading comprehension, and as children's decoding accuracy levels increase with time, listening and reading comprehension also become more closely aligned (Hoover \& Gough, 1990). Indeed, the reports of very strong relationships between listening comprehension and reading comprehension among older readers with good word-recognition skills have provided unequivocal evidence for this assertion (Adlof, Catts \& Little, 2006; Hoover \& Gough, 1990; Tilstra, McMaster, Van den Broek, Kendeou \& Rapp, 2009).

Following on from this, the question arises as to what might be the key component processes of text comprehension. There is no question that reading comprehension is a multifaceted process that may not only be influenced by the components of oral language processing skills (e.g., morphosyntactic skills and vocabulary), but also by other cognitive skills, such as executive functions and higher-level meta-cognitive skills (e.g., inference making). Additionally, factors such as background knowledge, motivation and text characteristics (e.g., genre) may also influence comprehension processes (for reviews, see Oakhill \& Cain, 2007; Perfetti, Landi \& Oakhill, 2005; Westby, 2004). There is less research on listening comprehension; nonetheless, these factors are also likely to play similar roles in listening comprehension. Most research on L2 reading comprehension has focused on the role of oral language and in particular, vocabulary and morphosyntactic skills (for a review, see Lesaux et al., 2006). Certainly, any weakness or developmental delay at core oral language skills may act as a bottleneck and constrain the ability to engage in higher-level comprehension processes, such as inference making and integration. Hence, there is much merit in further advancing our understanding of the role of oral language skills in L2 text comprehension and it is for this reason that oral language will be the focus of the current study. 
Vocabulary knowledge is by far the most commonly assessed semantic skill in this area of research. Understanding the meaning of words is clearly central for sentence comprehension (Nagy, 2007; Wagner, Muse \& Tannenbaum, 2007). Likewise, morphosyntactic skills, which entail syntactic (i.e., ordering of linguistic items) and morphological (i.e., internal structure of linguistic items) processing skills play a pivotal role in processes such as syntactic parsing which are also central for sentence comprehension (Carlisle, 2007; Scott, 2004). Vocabulary and morphosyntactic skills may also facilitate word-recognition skills (Bowey, 2005; Carlisle, 2004) and thereby indirectly support reading comprehension. For instance, vocabulary knowledge has been found to facilitate the recognition of irregular words (Ricketts, Nation \& Bishop, 2007). Increased exposure to written and spoken language, and facility in text comprehension, in turn, may support the acquisition of new vocabulary and morphosyntactic knowledge (Nagy, Anderson \& Herman, 1987). In fact, reading itself becomes one of the primary means of acquisition of new vocabulary (for reviews, see McGregor, 2004; Nagy, 2007).

Hence, a complex and mutually facilitating relationship is likely to form as children's reading, oral language and comprehension skills develop over time. Although the details of the proposed dynamic relationships remain to be clarified and supported by research evidence (Scott, 2009; Wagner et al., 2007), a large number of cross-sectional and longitudinal studies have reported powerful relationships between oral language and reading comprehension skills among both L1 (e.g., Babayiğit \& Stainthorp, 2011; De Jong \& van der Leij, 2002; Nation \& Snowling, 2004) and L2 learners (e.g., Nakamoto, Lindsey \& Manis, 2007; Proctor, Carlo, August \& Snow, 2005). These findings are also in accordance with the reports that oral language weaknesses are among the primary factors contributing to reading comprehension difficulties (e.g., Adlof, Catts \& Lee, 2010; Catts, Fey, Zhang \& Tomlin, 1999; Nation, Clarke, Marshall \& Durand, 2004; Nation, Cocksey, Taylor \& Bishop, 2010).

\section{Oral language and text comprehension of L1 and L2 learners: a review of comparative studies}

Numerous studies on L2 reading comprehension have found that whereas L1 and L2 learners at primary school levels tend to perform on a par on the measures of word-recognition accuracy and speed, L2 learners tend to underperform on the measures of text comprehension, vocabulary and morphosyntactic skills (e.g., Burgoyne et al., 2009, 2010; Droop \& Verhoeven, 2003; Frederickson \& Frith, 1998; Geva \& Farnia, 2011; Hutchinson et al., 2003; Nakamoto et al., 2007; Stuart, 2004).

For instance, Hutchinson et al. (2003) followed 43 L1 and 43 L2 learners in England from 7 to 9 years of age and assessed their oral language and reading skills in English. L2 learners' home languages were mostly Gujarati, Urdu and Punjabi. There were no language group differences in word-reading accuracy levels at any testing point, but there was a significant L1 advantage on the measures of listening comprehension, reading comprehension, vocabulary and grammar across all testing times. In this study, aspects of oral language skills were significant predictors of both reading and listening comprehension. Further corroborating evidence for these findings came from a study on $46 \mathrm{~L} 1$ and $46 \mathrm{~L} 2$ English-speaking learners from similar home language backgrounds by Burgoyne et al. (2009). In this study, although the L2 learners outperformed their L1 peers on the measures of word-recognition accuracy, they underperformed on the measures of vocabulary and 
text comprehension. Droop and Verhoeven (2003) also noted similar developmental delay in oral language, listening comprehension and reading comprehension of Dutch-speaking L2 learners even after taking into account socioeconomic status (SES) differences between the groups. These studies have also highlighted that the observed reading comprehension difficulties of L2 learners were not confined to written text and that it is equally important to examine L2 listening comprehension proficiency.

Very few studies have explicitly tested the extent to which oral language skills contributed to the observed L1 and L2 developmental gap in reading comprehension levels. One notable study by Lervåg and Aukrust (2010) followed Norwegian-speaking L1 and L2 learners from about 7.5 to 9 years of age. The growth curve analysis showed that initial developmental lag in L2 learners' vocabulary levels at the beginning of formal reading instruction was the primary factor contributing to the observed developmental delay in their later reading comprehension levels even when adjustments were made for mother's education, nonverbal ability and decoding skills. Similar results were reported by Nakamoto et al. (2007) who followed Spanish-speaking English language learners from the first to seventh grade in the United States.

The next question relates to the extent to which the strength of the relationships between oral language and reading comprehension skills are comparable across the L1 and L2 groups. Several studies reported similarities as well as notable differences across the two language groups (e.g., Droop \& Verhoeven, 2003; Geva \& Farnia, 2011; Hutchinson et al., 2003; Stuart, 2004; Verhoeven, 2000). For instance, Droop and Verhoeven (2003) followed children from the third to fourth grade ( $8-10$ years of age) and reported stronger effect of vocabulary skills on both reading comprehension and listening comprehension levels of the Dutch-speaking L2 learners. Conversely, morphosyntactic skills (sentence imitation) were found to play a stronger role in L1 reading comprehension and listening comprehension. Likewise, in Hutchinson et al.'s (2003) study, expressive vocabulary was a unique predictor of L2 but not L1 reading comprehension and listening comprehension levels. Hence, although the details differed these findings suggested that the pattern of relationships between oral language and comprehension may differ across the L1 and L2 groups.

Against the background of these findings, there are several contradictory findings that need to be considered. In a series of large-scale studies Lesaux, Siegel and colleagues have found that English-speaking Canadian L1 and L2 learners performed at comparable levels on the measures of reading comprehension (Lesaux, Lipka \& Siegel, 2006; Lesaux, Rupp \& Siegel, 2007; Lesaux \& Siegel, 2003). For instance, Lesaux et al. (2007) followed children from kindergarten to the fourth grade and in contrast to the previous reports (e.g., Lervåg and Aukrust, 2010), found that L1 and L2 groups performed on a par on reading comprehension and their developmental trajectories were remarkably similar. At least one study has also reported L2 advantage on the measures of reading comprehension. Chiappe, Glaeser and Ferko (2007) found that Korean-English speaking L2 learners in the United States outperformed their native English-speaking peers on an English reading comprehension measure at the beginning of Grade 1 (mean age $=6.6$ years). Interestingly, in this study, the L2 learners performed very well on reading comprehension despite their relatively more limited English vocabulary skills. Similar paradoxical findings were also reported by Lesaux and Siegel (2003), who found that despite significant weaknesses in their syntactic skills, L2 learners performed on a par with their L1 peers on a reading comprehension task.

Finally, although there are reports that aspects of oral language skills might be differentially related to L1 and L2 comprehension (e.g., Droop \& Verhoeven, 2003), there is 
also evidence of comparable relationships (e.g., Lesaux et al., 2006, 2007; Van Gelderen et al., 2003). In fact, very few studies explicitly tested the statistical significance of the observed differences in the strength of relationships across the two language groups. For instance, Van Gelderen et al. (2003) used a multi-group structural equation modelling to specifically examine this issue and found that the effect (i.e., path weights) of oral language (vocabulary and grammar), as well as meta-cognition and speed of processing on reading comprehension levels was comparable across the different Dutch-speaking L1 and L2 groups even though there were significant group differences in reading comprehension levels. Along similar lines, Lesaux et al. (2007) found that kindergarten predictor measures, which also included a measure of syntactic skills (cloze task) played a comparable role in reading comprehension levels of the English-speaking Canadian L1 and L2 groups. It is not entirely clear to what extent contextual (e.g., sociocultural factors, educational experiences) and methodological differences might have contributed to these seemingly contradictory findings (for a detailed discussion, see Lipka et al., 2005). Nonetheless, these findings highlighted the importance of clarifying the relative role of oral language in L2 text comprehension.

\section{Current study}

The present study seeks to augment our understanding of the oral language and text comprehension skills of L1 and L2 learners and addresses three guiding research questions.

1. To what extent do English-speaking L2 learners in England lag behind their L1 peers in oral language and text comprehension? In essence, the study seeks to confirm and take further the previous reports on L2 learners in England and examine the language group differences after accounting for the duration of formal schooling in English, which is undoubtedly an important factor that needs to be taken into account when evaluating the results. Following the previous reports on L2 learners in England (e.g., Hutchinson et al., 2003), it was anticipated that there would be a significant L1 advantage on oral language and text comprehension but not on word recognition. The next question is essentially an extension of the first question, as it is contingent on the anticipated group differences in text comprehension levels.

2. To what extent can language group differences in text comprehension levels be explained by oral language skills? There is no question that vocabulary and morphosyntactic skills are central for text comprehension (Nagy, 2007). Given the reports that L2 learners' oral language proficiency tends to lag behind, which may then constrain their text comprehension (e.g., Lervåg \& Aukrust, 2010), it was anticipated that oral language would explain language group differences in text comprehension levels.

3. To what extent does the relationship between oral language and text comprehension levels vary by language group? Limited research evidence and mixed findings impede the formulation of precise predictions about the relative role of oral language skills in L1 and L2 learners' text comprehension levels. Nevertheless, if oral language plays a more significant role in L2 learners' text comprehension levels, then it would be expected to explain a significantly larger amount of the variance in L2 learners' text comprehension levels. If, however, oral language plays an equally important role in L1 and L2 learners' text comprehension levels, then the magnitude of the explained variance would be expected to be comparable across the two language groups. 


\section{Methods}

\section{Participants}

One hundred and twenty-five children ( $M=121.46$ months, $S D=4.65$, ranged between 110 and 130 months) at Year 5 (9-10 years of age) participated in the study. The primary school runs from reception (4-5 years of age), then Year 1 (6-7 years of age) to Year 6 (10-11 years of age) in England. Children who have been attending a primary school in England less than 4 years and those on the Special Education Needs register were excluded from the study. Excluding recent arrivals was considered important to ensure that the L2 learners have had the opportunity to develop sufficient levels of English oral language and word-reading skills to enable a reliable assessment of their text comprehension levels in English. In this way, it was also ensured that the L1 and L2 groups were reasonably comparable in terms of exposure to formal education in England.

Children were recruited from eight primary schools in south-west England. The proportion of students in receipt of free school meals was higher than the national average in seven out of the eight participating schools, suggesting that the current sample was likely to have come from lower SES backgrounds. The data collection was conducted over two waves: 72 children ( $35 \mathrm{~L} 1$ and $37 \mathrm{~L} 2$, male:female $=37: 35)$ were tested at the first wave and 53 children ( $21 \mathrm{~L} 1$ and $32 \mathrm{~L} 2$, male:female $=32: 21$ ) were tested at the second wave. Preliminary analysis confirmed that the scores of the two cohorts of children did not differ on any of the measures (see Table A1). There were also no statistically significant differences across the two cohorts in the observed distribution of sex ratio, $\chi^{2}(1, N=125)=$ $0.67, p=.414$, or the proportion of L2 and L1 learners, $\chi^{2}(1, N=125)=0.67, p=.414$. Following from this, further analyses confirmed that the pattern of correlation coefficients between the measures across the two cohorts was comparable (i.e., none of the differences in correlation coefficients were significant). These findings suggested that it was appropriate to combine the two cohorts into a single sample in order to improve the statistical power of the study. There was, however, a significant difference in the distribution of the age of the two cohorts, mean difference $=3.1$ months; $t(123)=4.20, p<.001$. For this reason, age has been controlled for in all the reported statistical analysis.

Hence, in the combined sample, there were a total of $56 \mathrm{~L} 1$ learners $(M=121.02$ months, $S D=4.91 ;$ range $=110-130$ months; male:female $=29: 27)$ and 69 L2 learners $(M=121.81$ months, $S D=4.43$; range $=112-129$ months; male:female $=40: 29)$. The L2 learners spoke at least one language other than English at home. None of the L1 learners was a fluent speaker of another language or spoke a language other than English at home. The two language groups also did not significantly differ in terms of the distribution of age, $t(125)=$ $-0.95, p=.345$ or sex ratio, $\chi^{2}(1, N=125)=0.26, p=.610$.

The information about language background of the children and the duration of attendance at school in England was obtained from school reports and class teachers as well as children. There were 15 different home languages spoken by the L2 learners in this study": Somali $(n=20,29 \%)$, Urdu $(n=16,23 \%)$, Punjabi $(n=6,9 \%)$, Serbian $(n=5,7 \%)$, Arabic $(n=5,7 \%)$, Bengali $(n=5,7 \%)$, Bulgarian $(n=1,1 \%)$, Sylheti $(n=1,1 \%)$, Polish $(n=2$, $3 \%)$, Portuguese $(n=1,1 \%)$, Hungarian $(n=1,1 \%)$ and Spanish $(n=1,1 \%)$. There were also five trilingual L2 learners who along with English reported to speak Somali and Dutch $(n=1,1 \%)$, Somali and Italian $(n=1,1 \%)$, Dutch and Arabic $(n=2,3 \%)$ and Spanish and

Note: Correction added on 15 September 2012 after initial online publication on 23 August 2012. The data for Somali and Urdu home language speakers has been corrected in this version of the article. 
Romanian $(n=1,1 \%)$. The L2 learners in this sample reported to have very limited (e.g., the ability to read several words) or no literacy skills in their home languages.

At the time of writing, there was no official source of information about the exact percentage of languages spoken in the United Kingdom (Aspinall, 2007). According to one estimate, the top 10 most frequently spoken home languages in England were Panjabi, Urdu, Bengali, Gujarati, Somali, Polish, Arabic, Portuguese, Turkish and Tamil, respectively (Centre for Information on Language Teaching and Research [CILT], The National Centre for Languages, 2011). Based on this information, it can be said that the L2 sample in this study was reasonably representative of the national profile of ethnic minority languages in the UK.

\section{Materials and procedure}

The testing was conducted on a one-to-one basis at children's school in a quiet room. The tasks were implemented in the same fixed order across all the children and the whole testing battery was implemented in two sessions each lasting for about 25 minutes. The author and three research assistants who were trained by the author conducted all the testing sessions. All the sessions were recorded with a digital voice recorder for further verification and cross-validation.

Reading. The Neale Analysis of Reading Ability-Second Revised British Edition (NARAII) (Neale, 1997), which is one of the most widely used standardised tests of reading comprehension in England was implemented to assess children's reading skills. In this test, children read aloud a series of increasingly more difficult passages followed by openended oral comprehension questions to which they needed to provide oral answers. In the NARA-II, children's word-reading errors are corrected and testing is stopped when the word-reading error rate reaches a certain threshold. As several researchers have found (Burgoyne et al., 2010), the testing procedure of the NARA-II can complicate group comparisons, as more accurate word readers can progress further on the test attempting more comprehension questions. This, in turn, may mean that children in two groups may read different sets of passages (for a fuller discussion, see Cain \& Oakhill, 2006). Hence, in this study, in order to facilitate the group comparisons, all children were presented with the same set of passages (see Cain \& Oakhill, 2006) and children's word-reading errors were not corrected. Instead, children were instructed to try their best with any difficult word and if they still found it difficult to read, to move on to the next word. Several considerations underpinned this decision.

First, as the present study focused on older age groups and excluded children with learning difficulties, it was anticipated that children would have adequate word-recognition skills to enable a valid assessment of their reading comprehension skills without the need for correcting their word-reading errors. Second, word-reading errors can arise due to comprehension problems and both can also be linked to underlying vocabulary and morphosyntactic skills (Frederickson \& Frith, 1998). As the primary focus of the current study was to examine the role of oral language skills in reading comprehension processes, it was considered important to control for any possible bias that might arise by interfering with the word-reading errors. Finally, given that a listening comprehension test was also implemented in this study, it was possible to obtain an additional index of children's text comprehension levels independent of word-level reading skills. It is notable that, to date, no published study on L2 learners using the NARA-II has systematically addressed all these important methodological issues. 
The Level 1-3 passages from the Form 1 were used to test reading comprehension skills. After a practice passage, the three passages were presented to all children in the same order starting with the easiest passage at Level 1. Including a very easy passage at Level 1 was considered essential to ensure that all children would experience some success on this test. There was a total of 20 oral questions (based on the three selected passages); hence, the maximum possible reading comprehension score was 20. Children were free to refer back to the passage whilst answering the questions and one mark was allocated for each accurate answer. The questions in this test were designed to assess verbatim memory of the text and general understanding as well as some inference-making skills. The internal consistency of the comprehension scores across the three passages was high in this study: the Cronbach's alpha coefficient was .80.

The word-reading accuracy was calculated by subtracting the total number of reading errors from the total number of words of the three passages (which was 151). The total time taken to read each passage was also recorded which in turn enabled calculation of a reading speed score indexed in terms of the number of accurately read words per minute.

Listening comprehension. The Understanding Spoken Paragraphs subtest from the Clinical Evaluation of Language Fundamentals-Fourth UK Edition (CELF-4 ${ }^{\mathrm{UK}}$; Semel, Wiig \& Secord, 2006) was used to assess listening comprehension skills. The comprehension questions following each spoken narrative paragraph were designed to examine the ability to understand the main idea of the spoken text, recall a detailed piece of information, sequence the elements of the story and make inferences and predictions (Semel et al., 2006). In order to ensure that there is consistency in the implementation of the passages across the three different testers, each paragraph was recorded by a native female speaker of English language with a normal prosody and played to the children. In this test, children listened to each story once and then they were asked to answer five oral questions as best they could. Following the guidelines in the test manual, the three passages set for the age groups ranging from 9:00 to 10:11 years were presented to all children. The maximum possible score for this task was 15 and the Cronbach's alpha coefficient of this subtest in this study was .79.

Vocabulary. The British Picture Vocabulary Scale-II (BPVS-II; Dunn, Dunn, Whetton \& Burley, 1997) was used to assess children's receptive vocabulary skills. The reliability indices (i.e., Cronbach's alpha internal reliability and split-half) of this test for children aged between 9 and 11 years were reported to range from .89 to .97 in the test manual (Dunn et al., 1997).

Morphosyntactic skills. The Recalling Sentences subtest from the CELF-4 ${ }^{\mathrm{UK}}$ (Semel et al., 2006) was used as a broad measure of children's morphosyntactic skill. The Recalling Sentences subtest is essentially a sentence imitation (repetition) test: sentences with increasing length and grammatical complexity were read aloud and the task was to repeat the sentences back in exactly the same way. The split-half internal reliability indices of this subtest for age groups between 9 and 11 years were reported to be very high, .92 and .90 , respectively (Semel et al., 2006).

It is widely acknowledged that imitation is not a passive copying process but an active reconstructive process, and in the linguistic research, it is widely acknowledged that to be able 'to imitate a structure, the structure must be ... part of the child's grammatical competence' (Lust, Flynn \& Foley, 1996, p. 56). Hence, sentence imitation tasks have been widely used as a measure of morphosyntactic skills (e.g., Devescovi \& Cristina Caselli, 2007; Droop \& Verhoeven, 2003; Nakamoto et al., 2007; Verhoeven, 1990) and have been found to be a reliable indicator of implicit oral language skills of second language learners 
(Erlam, 2006). In addition, sentence imitation tasks have been found to be a very reliable marker of specific language impairment (Conti-Ramsden, Botting \& Faragher, 2001) and reading difficulties (Adlof et al., 2010; McCardle, Scarborough \& Catts, 2001).

Although sentence imitation tests also involve verbal memory skills, there is evidence of unique links of sentence imitation with both reading comprehension and oral language comprehension levels over and above the verbal short-term and working memory skills (Alloway \& Gathercole, 2005). These findings have led to the conclusion that along with verbal working memory, long-term memory (e.g., morphosyntactic knowledge) skills were also likely to underlie the reported strong relationships between the sentence imitation and text comprehension measures (Alloway \& Gathercole, 2005). This conclusion is certainly in line with the reports from the linguistic studies that sentence imitation is a reconstructive process and can be used as a reliable tool to assess the long-term memory representations of morphosyntactic structures (e.g., see Ellis, 2005; Erlam, 2006; Lust et al., 1996).

Digit memory span. The Number Repetition subtest (numbers forwards and numbers backwards) from the CELF-4 ${ }^{\mathrm{UK}}$ (Semel et al., 2006) was used as an index of verbal memory skills. The standard procedures of implementation and scoring were followed. The scores on the forwards and backwards repetition subtests were summed to form a composite measure of verbal memory skills. The split-half internal reliability indices of this subtest in this study ranged from .89 to .91 .

In this study, digit memory span was used as a control measure of verbal memory skills. The performance on the Recalling Sentences subtest as well as text comprehension measures in this study were likely to be influenced by verbal memory skills, hence controlling for digit span would enable examination of the unique role of oral language skills in text comprehension relatively independent from verbal memory skills.

Matrix reasoning. The Matrix Reasoning subtest from the Wechsler Intelligence Scale for Children-Fourth UK Edition (Wechsler, 2003) was used as a control measure of general nonverbal reasoning skills. The subtest simply involves selection from a number of options a pattern that completes best the missing part of a larger visual array. Although it is widely acknowledged that no test can be completely free from language and cultural bias, as the matrix reasoning types of tests rely on visual input and do not require a verbal response, they are generally regarded to minimise the possible cultural and language bias inherent in any standardised reasoning test (see Wechsler, 2003) and therefore are considered acceptable to be used among populations from diverse language and cultural backgrounds (e.g., see Bialystok \& Martin, 2004; Geva, 2000; Hutchinson et al., 2003). The split-half internal reliability indices of this test have been reported to range from .89 to .92 for age groups between 9 and 11 years (Wechsler, 2003).

\section{Results}

Table 1 presents a summary of descriptive statistics as well as group differences examined with a series of ANCOVA with age as the covariate. Due to the concern that the use of standard scores might be inappropriate for children from diverse language and cultural backgrounds, the analyses were conducted with both raw and standard scores. The results, however, were very similar across the two types of scores. Therefore, it was considered appropriate to simplify the presentation of the findings by including only the raw scores in Table 1. (A summary of the standard scores can be obtained from the author.) 


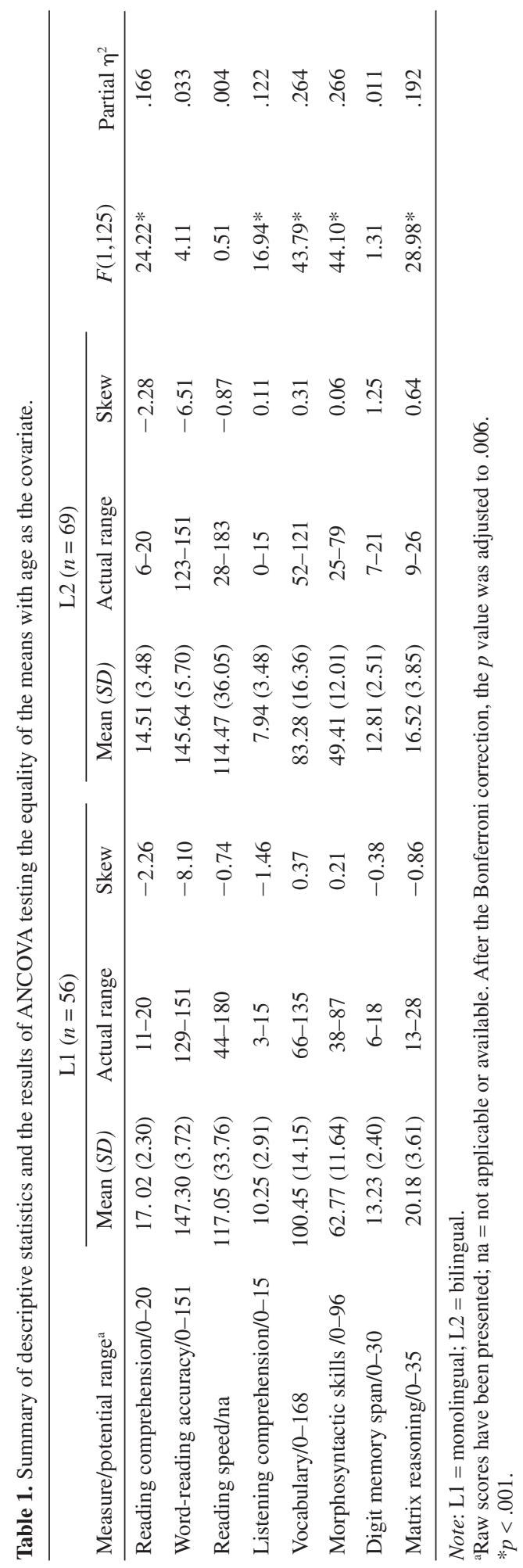


Table 2. Summary of partial intercorrelations between the measures after controlling for age.

\begin{tabular}{|c|c|c|c|c|c|c|c|c|c|}
\hline & & 1 & 2 & 3 & 4 & 5 & 6 & 7 & 8 \\
\hline 1. & Reading comprehension & - & & & & & & & \\
\hline 2. & Word-reading accuracy & $.50 * *$ & - & & & & & & \\
\hline 3. & Reading speed & $.39 * *$ & $.63 * *$ & - & & & & & \\
\hline 4. & Listening comprehension & $.68 * *$ & $.37 * *$ & $.32 * *$ & - & & & & \\
\hline 5. & Digit memory span & $.24 *$ & $.30 * *$ & $.28^{*}$ & .13 & - & & & \\
\hline 6. & Matrix reasoning & $.36^{* *}$ & $.25^{*}$ & .18 & $.46^{* *}$ & .02 & - & & \\
\hline 7. & Vocabulary & $.59 * *$ & $.41 * *$ & $.38 * *$ & $.67 * *$ & .17 & $.56^{* *}$ & - & \\
\hline 8. & Morphosyntactic skills & $.60 * *$ & $.44 * *$ & $.39 * *$ & $.66^{* *}$ & $.38 * *$ & $.47 * *$ & $.73 * *$ & - \\
\hline
\end{tabular}

Note: $N=125$. After the Bonferroni correction, the $p$ value was adjusted to .006 . $* p<.01 ; * * p .001$.

With the exception of digit memory span, word-reading accuracy and reading speed, the L1 group scored reliably higher than the L2 group on all the measures and the effect sizes tended to be large (all partial eta-squared values, except that for listening comprehension, were larger than .14, see Cohen, 1988).

According to the formal procedure of the NARA-II, testing terminates when children make more than 16 word-reading errors on the Level 1-3 passages, and they are not presented with comprehension questions. In this study, only one L1 pupil made 17 wordreading errors and one L2 pupil made 20 errors on the Level 3 passage. The removal of these two cases from the analysis did not change the overall findings reported throughout this paper; for this reason, these two cases were retained in the analysis.

\section{Correlation analysis}

Prior to the correlation analysis, the data were screened for outliers and the normality of distribution of the scores. An absolute skew index value greater than 1.96 suggests a statistically significant skew at $p<.05$ (Field, 2005). As Table 1 shows, there was a significant negative skew on the reading comprehension and word-reading accuracy measures. There were also three outlying low scores on the word-reading accuracy measure. Following the guidelines of Tabacknick and Fidell (2001), the low word-reading accuracy scores were changed to the next highest score. However, this did not improve the distribution of the scores. Therefore, further data transformation was conducted, which involved the logarithm-10 transformation of reflected scores, which has improved the distribution of the scores and these scores were used in the subsequent analysis. Likewise, a square-root transformation of the reflected reading comprehension scores has improved the distribution of the scores. However, the results based on the transformed scores were essentially the same. In order to facilitate the interpretation of the reported results, the untransformed reading comprehension scores have been used in the analyses. Finally, although gender differences in reading comprehension skills of L2 learners have been reported before (e.g., Neale, 1997), gender was not related to any of the measures in this study. Therefore, gender was excluded from the analysis.

Table 2 shows a summary of the results of the partial correlation analyses between the measures with age as the covariate measure. There were strong correlations between the reading comprehension and listening comprehension and likewise, between vocabulary and morphosyntactic skills. The two oral language measures were clearly the most powerful correlates of both reading comprehension and listening comprehension. Finally, 
Table 3. Multiple regression analyses: predictors of reading comprehension levels.

\begin{tabular}{|c|c|c|}
\hline & $\Delta R^{2}$ & $\beta$ \\
\hline \multicolumn{3}{|l|}{ Model 1} \\
\hline Intercept & & -.74 \\
\hline Age & & .03 \\
\hline Matrix reasoning & & .01 \\
\hline Digit memory span & & .01 \\
\hline Word-reading accuracy & & $.25^{* *}$ \\
\hline Reading speed & & .02 \\
\hline Morphosyntactic skills & & $.28 * *$ \\
\hline Vocabulary & & $.26 *$ \\
\hline Total $R^{2}$ (adjusted $R^{2}$ ) & $.48 * * *(.45)$ & \\
\hline \multicolumn{3}{|l|}{ Model 2} \\
\hline $\begin{array}{l}\text { Step } 1 . \text { Age, matrix reasoning, digit memory span, word-reading accuracy, } \\
\text { reading speed }\end{array}$ & $.34 * * *$ & \\
\hline Step 2a. Language status (L1, L2) & $.07 * * *$ & $-.29 * * *$ \\
\hline Step 2b. Oral language & $.13 * * *$ & \\
\hline Vocabulary & & $.23 *$ \\
\hline Morphosyntactic skills & & $.24 *$ \\
\hline Step 3b. Language status (L1, L2) & .01 & -.13 \\
\hline \multicolumn{3}{|l|}{ Model 3} \\
\hline Step 1. Age, vocabulary, morphosyntactic skills & $.42 * * *$ & \\
\hline Step 2. Language status (L1, L2) & .00 & -.08 \\
\hline \multicolumn{3}{|l|}{ Model 4} \\
\hline $\begin{array}{l}\text { Step } 1 . \text { Age, matrix reasoning, digit memory span, word-reading accuracy, } \\
\text { reading speed, vocabulary, morphosyntactic skills, language status }\end{array}$ & $.49 * * *$ & \\
\hline Step 2a. Language status $\times$ vocabulary & $.03 *$ & $.28 *$ \\
\hline Step 2b. Language status $\times$ morphosyntactic skills & $.03 *$ & $.27 *$ \\
\hline
\end{tabular}

Note: $\mathrm{L} 1=$ monolingual; $\mathrm{L} 2=$ bilingual.

${ }^{*} p<.05 ; * * p<.01 ; * * * p<.001$.

word-reading accuracy and reading speed were also related to reading comprehension. Table A2 shows a summary of the partial correlation coefficients between the measures as a function of the language group.

\section{Multiple regression analysis}

The preliminary checks confirmed that there were no violations of the assumptions of multiple regression analysis. Following from this, a series of multiple regression analyses were conducted to examine (a) the role of oral language in text comprehension levels over and above verbal memory and nonverbal reasoning skills, (b) to what extent oral language explained language group differences in text comprehension levels and (c) whether the role of oral language in reading comprehension differed across the L1 and L2 groups. Table 3 shows a summary of the results for reading comprehension and Table 4, for listening comprehension. 
Table 4. Multiple regression analyses: predictors of listening comprehension levels.

\begin{tabular}{|c|c|c|}
\hline & $\Delta R^{2}$ & $\beta$ \\
\hline \multicolumn{3}{|l|}{ Model 1} \\
\hline Intercept & & .11 \\
\hline Age & & -.00 \\
\hline Matrix reasoning & & .09 \\
\hline Digit memory span & & -.09 \\
\hline Morphosyntactic skills & & $.42 *$ \\
\hline Vocabulary & & $.36^{*}$ \\
\hline Total $R^{2}$ (adjusted $\left.R^{2}\right)$ & $.53 *(.51)$ & \\
\hline \multicolumn{3}{|l|}{ Model 2} \\
\hline Step 1. Age, matrix reasoning, digit memory span & $.24 *$ & \\
\hline Step 2a. Language status (L1, L2) & $.02^{\dagger}$ & $-.17^{\dagger}$ \\
\hline Step 2b. Oral language & $.29 *$ & \\
\hline Vocabulary & & $.35^{*}$ \\
\hline Morphosyntactic skills & & $.44^{*}$ \\
\hline Step 3b. Language status (L1, L2) & .01 & -.09 \\
\hline \multicolumn{3}{|l|}{ Model 3} \\
\hline Step 1. Age, vocabulary, morphosyntactic skills & $.51 *$ & \\
\hline Step 2. Language status (L1, L2) & .00 & .07 \\
\hline \multicolumn{3}{|l|}{ Model 4} \\
\hline $\begin{array}{l}\text { Step 1. Age, matrix reasoning, digit memory span, vocabulary, } \\
\text { morphosyntactic skills, language status }\end{array}$ & $.53^{*}$ & \\
\hline Step 2a. Language status $\times$ vocabulary & .00 & .02 \\
\hline Step 2b. Language status $\times$ morphosyntactic skills & .01 & .13 \\
\hline
\end{tabular}

Note: $\mathrm{L} 1=$ monolingual; $\mathrm{L} 2=$ bilingual. ${ }^{\dagger} p=.058 ;{ }^{*} p<.001$.

Reading comprehension. Model 1 in Table 3 shows the results of simultaneous multiple regression analysis with reading comprehension as the outcome measure. Word-reading accuracy, vocabulary and morphosyntactic skills were the unique predictors of reading comprehension over and above verbal memory and nonverbal reasoning skills. The overall model explained a large amount of the variance $(48 \%)$ in reading comprehension levels, $F(7,117)=15.20, p<.001$.

Model 2 in Table 3 examined to what extent oral language skills explained language group differences in reading comprehension levels with a series of hierarchical multiple regression analyses. For this purpose, language status was coded as a dummy variable (L1 = 0 and L2 =1) and included in the model before and after the two oral language measures. The results revealed that even when individual differences in age, verbal memory, nonverbal reasoning and word-reading skills were accounted for, language status remained as a significant unique predictor and explained a small-to-moderate amount of the variance $(7 \%)$ in reading comprehension levels. In other words, controlling for verbal memory, nonverbal reasoning and word-recognition skills did not eliminate the language group differences in reading comprehension levels. However, when language status was entered into 
the regression model after oral language skills at Step 3, its effect became nonsignificant (Model 2, Table 3). Model 3 (Table 3) added further strength to these results by showing that even when oral language alone was entered into the regression model at the first step, the effect of language status became nonsignificant. Together, these findings showed that individual differences in oral language skills (i.e., vocabulary and morphosyntactic skills) explained the language group differences in reading comprehension levels.

Following from this, Model 4 (Table 3) examined to what extent the magnitude of the effect of vocabulary and morphosyntactic skills on reading comprehension levels varied as a function of the language status. For this purpose, two interaction terms were formed by computing the product of language status with vocabulary and morphosyntactic skills (see Cohen \& Cohen, 1983; Jaccard, Turrisi \& Wan, 1990). The effects of both interaction terms were small, albeit statistically significant, suggesting that both vocabulary and morphosyntactic skills explained a larger amount of the variance in L2 learners' reading comprehension levels.

However, this result should be treated with some caution due to the observed heterogeneity of language group variances on reading comprehension (the Levene's test was significant at $p<.001$ ). To verify these results and further check for the homogeneity of error variance for the relationship between each independent variable and reading comprehension the computer program Alternative Tests for Moderated Multiple Regression (ALTMMR; http:// mypage.iu.edu/ haguinis/mmr/) was used (Aguinis, Petersen \& Pierce, 1999). DeShon and Alexander's rule of thumb, which states that error variance ratios should be less than 1:1.5, and Bartlett's $M$ test were used to assess homogeneity of error variances. The error variance ratios for vocabulary and morphosyntactic skills were 1:1.75 and 1:1.59, respectively. The Bartlett's test was significant for vocabulary but not for morphosyntactic skills, $M=4.617$, $p=.032$ and $M=3.192, p=.07$, respectively. Together these results suggested minor violations of the homogeneity assumption, hence the importance of conducting the alternative tests of moderation. The results of James' and Alexander's tests converged with those of the $F$ tests in that both showed that there was evidence for differential slopes for vocabulary $(U=4.989, U[$ Critical $]=3.917, p<.05 ; A=4.847, p=.028)$ and morphosyntactic skills $(U=9.261, U[$ Critical $]=3.917, p<.05 ; A=8.851, p=.003)$. Hence, the converging results from the three tests ( $F$ and the two alternative tests) improved the confidence in the observed moderator effects in this study (see Aguinis, 2004).

Listening comprehension. Broadly, the findings for listening comprehension were very similar in that both vocabulary and morphosyntactic skills were independent and powerful predictors, and the overall model explained a large amount of the variance (53\%) in listening comprehension levels, $F(5,119)=26.49, p<.001$ (see Model 1 in Table 4).

In addition, when oral language was entered into the regression model before the language status, group differences in listening comprehension levels became nonsignificant (Models 2 and 3, Table 4). Hence, these results suggested that individual differences in oral language skills explained the language group differences in listening comprehension levels. This broad statement, however, should be interpreted with some caution. This is because when language status was entered into the regression model before oral language but after age, matrix reasoning and verbal memory, its unique effect on listening comprehension was small and marginally significant (see Model 2, Table 4). It seems that matrix reasoning, which was more strongly related to listening comprehension than reading comprehension (see Table 2), captured some of the language group variance in listening comprehension levels, and thereby reduced the unique effect of language status on listening comprehension. This was evidenced by the finding that the removal of matrix reasoning from Step 1 in 
Model 2 (Table 4) substantially increased the unique effect of language status on listening comprehension ( $\Delta R^{2}$ increased from $2 \%$ to $\left.11 \% ; \beta=-.34, p<.001\right)$.

Finally, in contrast to reading comprehension, none of the interaction effects were significant, suggesting that the magnitude of the effects of the two oral language measures on listening comprehension were comparable across the L1 and L2 groups (Model 4, Table 4).

It is noteworthy that there was no evidence for violation of homogeneity of error variance for either vocabulary (error variance ratio $=1: 1.43, M=1.912, p=.167$ ) or morphosyntactic skills (error variance ratio $=1: 1.13, M=0.233, p=.630$ ). The results from the ALTMMR have also further confirmed those of the $F$ tests. James' and Alexander's tests did not reveal any evidence for differential slopes for either vocabulary $(U=0.019, U$ $[$ Critical $]=3.919, p>.05 ; A=0.0191, p=.890)$ or morphosyntactic skills $(U=2.171, U$ $[$ Critical $]=3.919, p>.05 ; A=2.133, p=.144)$.

\section{Discussion}

Broadly, the findings were in line with the expectations. There was a significant L1 advantage on the measures of oral language and text comprehension but not on word-recognition accuracy or reading speed. Most importantly, the findings indicated that weaknesses in L2 learners' oral language skills explained their lower performance on both listening and reading comprehension. As regards the relative role of oral language across the L1 and L2 groups, the findings were less consistent. Although there was a tendency of oral language to play a more significant role in L2 learners' reading comprehension levels, parallel results were not observed for listening comprehension.

\section{To what extent do English-speaking L2 learners in England lag behind their L1 peers in oral language and text comprehension?}

The findings from this study converged with those from the previous reports (e.g., Burgoyne et al., 2009; Hutchinson et al., 2003; Stuart, 2004), and further contributed to this field of research by providing evidence that even when English-speaking L2 learners have received at least 4 years of formal schooling in England, they tended to underperform on the measures of listening comprehension, reading comprehension and oral language skills. Moreover, there were no language group differences in either word-reading accuracy or speed, which supports the previous reports that text-level rather than word-level skills tend to be more challenging for some L2 learners (Lesaux et al., 2006).

To what extent can language group differences in text comprehension levels be explained by oral language skills?

In this study, vocabulary and morphosyntactic skills emerged as equally important component skills of text comprehension and both explained unique variance in reading comprehension and listening comprehension levels. The present study went further and tested the extent to which language group differences in text comprehension levels could be explained by these oral language skills. As anticipated, group differences in reading comprehension levels became unreliable when the influence of vocabulary and morphosyntactic skills was taken into account (Table 3). It is noteworthy that controlling for individual differences in nonverbal reasoning, verbal memory, word-reading accuracy and reading speed did not eliminate the language group differences in reading comprehension levels. Similar results were observed 
for listening comprehension: controlling for oral language skills eliminated group differences in listening comprehension levels. However, in this case, matrix reasoning was also a reliable predictor of language group differences in listening comprehension levels.

The powerful role of vocabulary and morphosyntactic skills in reading comprehension and listening comprehension was not surprising. However, to date no published study explicitly examined whether the reported L2 disadvantage in text comprehension levels could be explained by these two core oral language skills after taking into account individual differences in verbal memory, nonverbal reasoning skills and the duration of formal schooling in England. The findings from this study are also in accordance with the very few studies that examined both L2 learners' reading and listening comprehension skills (e.g., Droop \& Verhoeven, 2003; Hutchinson et al., 2003), and further signified the importance of examining L2 learners' broader linguistic comprehension skills. Needless to say, oral language comprehension is at least as vital as reading comprehension for effective curriculum access and learning.

The observed similar pattern of relationships of oral language with reading comprehension and listening comprehension has provided support for the reliability of the results. Moreover, the results are in line with the simple view of reading, which emphasises the similarities in component skills of listening comprehension and reading comprehension, and the importance of word-reading accuracy in reading comprehension (Hoover \& Gough, 1990). Although the failure of text reading speed to make a unique contribution to reading comprehension levels was unexpected, similar findings have been reported before among different groups of L2 (e.g., Proctor et al., 2005) as well as L1 learners (e.g., Adlof et al., 2006; Babayiğit \& Stainthorp, 2011). It is widely acknowledged that there is a complex and interactive relationship between reading speed and comprehension, and a fuller evaluation of this issue requires focused investigations with multiple measures of reading (Kuhn \& Stahl, 2003; Walczyk, 1994).

Finally, it is of note that not all L2 learners underperformed in this study. Table A3 shows the proportion of L2 learners who scored one standard deviation below the L1 means on oral language and text comprehension. Broadly, the results suggested between $43 \%$ and $57 \%$ of the L2 learners scored one standard deviation below the L1 group's means on text comprehension and oral language. These findings are in accordance with the previous reports of lower performance of L2 learners on the BPVS (Dunn, Dunn \& National Foundation for Educational Research, 2009; Mahon \& Crutchley, 2006; Whetton, 1997) and the NARA-II (Neale, 1997). It seems that the language group differences are observed even when care is taken not to include recent arrivals in the data analysis (see Dunn et al., 2009).

\section{To what extent does the relationship between oral language and text comprehension levels vary by language group?}

The present study also examined the extent to which oral language played a differential role in L1 and L2 learners' text comprehension levels and more specifically, whether there was any evidence to suggest that oral language played a more significant role in L2 learners' text comprehension. With respect to reading comprehension, there was a small but significant interaction effect, suggesting that both vocabulary and morphosyntactic skills tended to explain a larger amount of the variance in L2 learners' reading comprehension levels. Given the small effect sizes and the fact that no parallel results were obtained with listening comprehension, there was no strong evidence in this study to suggest that oral language played a more significant role in L2 learners' text comprehension levels. Hence, 
broadly, the results from this study were in accordance with the previous studies that have found a comparable pattern of relationships between oral language and reading comprehension across the L1 and L2 groups (e.g., Lesaux et al., 2006, 2007; Van Gelderen et al., 2003). However, moderator effect sizes tend to be small in applied psychological research, and it has been suggested that small effect sizes should not be dismissed, unless there is a clear understanding of the range of moderator effect sizes in a given area of research. Moreover, very large sample sizes are often needed to obtain significant results (Aguinis, Beaty Boik \& Pierce, 2005). Hence, before one can draw any firm conclusions, further nuanced investigations using larger sample sizes and a wider range of oral language and text comprehension measures are clearly needed. Only then would it be possible to address any measurement issues and thereby enable a more informed evaluation of these findings (see Aguinis, 2004). There are also other methodological issues that need to be considered when evaluating the observed results in this area of research.

\section{General limitations and future research}

The way in which text comprehension is assessed may have direct implications for the observed pattern of results (Andreassen \& Bråten, 2009; Cutting \& Scarborough, 2006; Keenan \& Betjemann, 2006). In this study, both reading and listening comprehension measures required an oral response and therefore, the ability to provide a coherent explanation or narrative output for the open-ended questions. Open-ended questions inherently confound comprehension with narrative expression skills (Spooner, Baddeley \& Gathercole, 2004). Given that narrative expression is itself an important aspect of oral language skills that non-native English-speaking learners may have difficulties with (Pearson, 2002), it is equally important to examine comprehension skills with multiple choice tests that may not tax L2 children's production skills to the same extent (see Spooner et al., 2004; Stuart, 2004).

Likewise, all the written and spoken passages in this study were narrative. As L2 learners have been found to struggle specifically with the academic decontextualised language (Cummins, 1979, 1980), it is possible that the group differences might have been even more pronounced in the case of texts with expository genre. Hence, there are clear pedagogical as well as theoretical implications for further clarification of the role of task-related factors (e.g., genre, silent reading, multiple choice type of questions) in L2 learners' listening and reading comprehension levels.

In this study, due to the lack of appropriate measures, it was not possible to assess L2 learners' oral language or text comprehension skills in their home languages. Therefore, inevitably, the present findings have provided a partial picture of L2 learners' overall oral language and comprehension skills. For instance, there is evidence that when L2 children's vocabulary skills were assessed in both languages, their combined vocabulary knowledge tended to be higher than or comparable to that of their L1 peers (for a review, see Bedore \& Peña, 2008). It is, however, noteworthy that there are studies on Spanish-speaking L2 learners in the United States that have assessed children's oral language skills in both Spanish and English, and found that there was limited transfer from Spanish oral language skills to English reading comprehension (e.g., Gottardo \& Mueller, 2009; Nakamoto, Lindsey \& Manis, 2008). Needless to say, this is a complex area of research and the findings can be influenced by a number of factors including L2 learners' level of proficiency in their respective languages as well as possible linguistic interactions between the first and second languages (for a recent review, see Melby-Lervåg \& Lervåg, 2011). Understanding of L2 
oral language and literacy development clearly necessitates the development of normative tests that can provide a sensitive analysis of L2 children's development in their respective languages (for a fuller discussion, see Bedore \& Peña, 2008; Carter et al., 2005).

Although the duration of formal schooling was taken into account in this study, information about the time of exposure to English language was also needed to further clarify the observed language group differences. Kieffer (2008), for instance, found that language minority children in the United States who were proficient in English at the beginning of kindergarten showed similar growth patterns to those of native speakers. At the time of writing, there was no published study that examined the role of the duration of exposure to English in text comprehension in England, and unfortunately, it was not possible to obtain this information in this study.

It is not possible to ascertain the precise source of the observed discrepant findings from the current study and those that did not find any L2 disadvantage in reading comprehension levels (e.g., Lesaux, Lipka et al., 2006). Differences in SES background might be one possible explanation (Lipka et al., 2005). In this study, although it was not possible to obtain detailed information about the SES backgrounds of the individual students, the proportion of students who were in receipt of free school meals was higher than the national average in all but one of the participating schools. Hence, the L2 learners in this study, who were mostly from minority language backgrounds, were also more likely to have come from lower SES backgrounds (DfES, 2006). It is well-established that children from socially disadvantaged background are more at risk of delayed language development which may, in turn, have repercussions for their later literacy development (Ginsborg, 2006). Clearly, further investigations on subgroups of L2 learners from diverse SES backgrounds are needed to clarify this issue and the findings from this study may not generalise to L2 learners from more diverse or higher SES backgrounds.

Previous research has shown that the developmental trajectories of different minority language groups might vary (e.g., Droop \& Verhoeven, 2003; Roberts, Mohammed \& Vaughn, 2010). Although similar nuanced investigations remain to be conducted in England, significant variations in academic achievement levels of different ethnic minority groups have been reported (Connor, Tyers, Modood \& Hilage, 2004; SFR, 2012; Strand, 2008; Strand \& Demie, 2005). In this study, due to the small number of children from each language group, it was not possible to examine this issue; therefore, the findings may not generalise to specific language groups or language groups that were not tested in the current study.

Educational experiences of L2 learners in England constitute another important factor that should be taken into account when evaluating these findings. In contrast to other countries, such as some parts of Canada and the United States (see August, 2008), nonnative speakers of English language and particularly those from minority language backgrounds do not normally receive instruction in their home languages as part of their formal schooling in England. In fact, in this study, very few L2 learners reported to have some, albeit very limited, literacy skills in their home languages. Yet, there is evidence suggesting that systemic and sustained L2 education may promote the development of oral English language skills and academic achievement levels of non-native English-speaking learners (Rolstad, Mahoney \& Glass, 2005; Thomas \& Collier, 2002).

The observed powerful relationships between the sentence imitation and reading comprehension clearly corroborated previous reports (e.g., Adlof et al., 2010; Nakamoto et al., 2007). The sentence recall subtest of the CELF-4 ${ }^{\mathrm{UK}}$ (Semel et al., 2006) provides a broad index of children's morphosyntactic skills (Seeff-Gabriel, Chiat \& Dodd, 2010). One way of taking these findings further would be to clarify which specific syntactic and 
morphological processing skills play the central role in text comprehension and whether this differs across the L1 and L2 groups. Only then will it be possible to develop focused enrichment or intervention programmes to support the oral language skills of children from diverse language backgrounds (see Thordardottir, 2010). Such focused intervention research would also serve to take the findings of this present study, which are currently correlational in nature, further, and examine the possible causal nature of these relationships.

\section{Educational implications}

There is no question that the observed underperformance of a substantial proportion of L2 learners on the measures of oral language and text comprehension needs to be pursued further. To what extent these results reflected a transient developmental delay, or more persistent weaknesses in oral language and comprehension skills, clearly warrants further investigation. Some have reported that it may take up to 5 or 7 years for non-native Englishspeaking learners to achieve grade-level performance in English (Cummins, 1980; Thomas $\&$ Collier, 2002). The findings in this study suggested that 4 or 5 years were not sufficient for a substantial proportion of L2 learners to catch up with their L1 peers, hence the need for longitudinal research to shed light on the developmental trajectories of L2 learners and possible long-term ramifications of the observed developmental lag in their English oral language and comprehension skills. For instance, the implications of these findings for the academic attainment of L2 learners on the national reading and writing tests remain to be clarified (see SFR, 2011).

Without doubt, the issues raised in relation to the roles of SES, home language proficiency and developmental trajectories of oral language and literacy skills of L2 learners have direct implications for accurate identification of oral language and literacy needs of children from diverse home backgrounds. Currently, there are outstanding questions about the accurate diagnosis of speech and language difficulties of L2 children (Bedore \& Peña, 2008; Stow \& Dodd, 2003), as well as the extent to which educational needs of L2 children from socially disadvantaged backgrounds are adequately recognised and addressed (see Cline \& Shamsi, 2000; DfES, 2005; Flynn \& Stainthorp, 2006).

Taken together, the findings echoed the calls for close monitoring and sustained support of children's oral language development that seems to be even more vital for L2 learners (see Lindsay, Dockrell, Desforges, Law \& Peacey, 2010). Specifically, L2 learners from lower SES backgrounds are more likely to receive less oral English language input at home (DfES, 2005). The distribution of language input across two or more languages means that L2 learners are likely to receive less input in any one of their languages in comparison with their L1 peers. At least one study in England has reported positive effects of an early enrichment programme on oral language and literacy development of children from diverse language backgrounds (Dockrell, Stuart \& King, 2010). There is evidence, albeit limited, suggesting that interventions targeting broader oral language skills can improve comprehension (e.g., Bowyer-Crane et al., 2008; Clarke, Snowling, Truelove \& Hulme, 2010). Likewise, several studies on L2 learners have reported positive effects of vocabulary training (e.g., Carlo et al., 2004; Lesaux, Kieffer, Faller \& Kelley, 2010; Proctor et al., 2009). As noted before, L2 literacy education has been found to be a significant factor contributing to positive developmental trajectories of L2 learners (Rolstad et al., 2005; Thomas \& Collier, 2002). Finally, L2 learners are also likely to benefit from systematic instruction in comprehension strategies, which is found to be one of the most effective ways of supporting text comprehension skills (Edmonds et al., 2009). There remains, however, much 
to be done to develop our understanding of the oral language and literacy development of different subgroups of L2 learners that would pave the way for evidence-based enrichment or educational programmes.

\section{Conclusions}

To sum up, the findings from the present study revealed that after about 4 or 5 years of formal schooling in English, more L2 learners tend to show significant developmental delay in their English language skills, and this seems to be one of the primary reasons contributing to their lower performance on the reading comprehension and listening comprehension measures. Although these findings need to be pursued further, the observed results clearly underscored the challenges facing the educators and policy-makers alike to meet the oral language and educational needs of learners from diverse language backgrounds with important and far-reaching implications for the socio-emotional and economic well-being of this increasing population of learners.

\section{Acknowledgements}

The author would like to thank Rachael Bowden, Clare Crabb and Jennifer Robertson for their assistance with the data collection, and the children and teachers who participated.

\section{Note}

1. The definition as well as differentiation of bilingualism may differ depending on the research focus or theoretical approaches (Hamers \& Blanc, 2000; Romaine, 1989). Within the context of the present study, the term bilingual (L2) learners is used to refer to pupils who speak one or more language other than the mainstream language at home that may be at any level of fluency and the exposure to the mainstream language may be simultaneous or sequential with respect to the exposure to other language or languages of the child. Other terms that are often used in this field of research include learners who speak English as an additional language (e.g., in England), English language learners (e.g., in the United States), English as a second language (e.g., in Canada), linguistic minority learners, and non-native speakers (for further information, see August \& Shanahan, 2008). Likewise, in this context, the term monolingual (L1) learners refers to children whose first language is the mainstream formal language and who do not speak any language other than the mainstream language at home.

\section{References}

Adlof, S.M., Catts, H.W. \& Little, T.D. (2006). Should the simple view of reading include a fluency component? Reading and Writing, 19, 933-958. doi:10.1007/s11145-006-9024z

Adlof, S.M., Catts, H.W. \& Lee, J. (2010). Kindergarten predictors of second versus eighth grade reading comprehension impairments. Journal of Learning Disabilities, 43, 332-345. doi:10.1177/0022219410369067

Aguinis, H. (2004). Regression analysis for categorical moderators. New York: Guilford Press.

Aguinis, H., Beaty, J.C., Boik, R.J. \& Pierce, C.A. (2005). Effect size and power in assessing moderating effects of categorical variables using multiple regression: A 30-year review. The Journal of Applied Psychology, 90, 94-107. doi:10.1037/0021-9010.90.1.94

Aguinis, H., Petersen, S.A. \& Pierce, C.A. (1999). Appraisal of the homogeneity of error variance assumption and alternatives to multiple regression for estimating moderating effects of categorical variables. Organizational Research Methods, 2, 315-339. doi:10.1177/109442819924001 
Alloway, T.P. \& Gathercole, S.E. (2005). The role of sentence recall in reading and language skills of children with learning difficulties. Learning and Individual Differences, 15, 271-282. doi:10.1016/j.lindif.2005.05.001

Andreassen, R. \& Bråten, I. (2009). Examining the prediction of reading comprehension on different multiplechoice tests. Journal of Research in Reading, 33, 263-283. doi:10.1111/j.1467-9817.2009.01413.x

Aspinall, P.J. (2007). Language ability: A neglected dimension in the profiling of populations and health service users. Health Education Journal, 66, 90-106. doi:10.1177/0017896907073797

August, D. (2008). Demographic overview. In D. August \& T. Shanahan (Eds.), Developing reading and writing in second-language learners. (pp. 19-26). Abingdon: Routledge.

August, D. \& Shanahan, T. (2008). Introduction and methodology. In D. August \& T. Shanahan (Eds.), Developing reading and writing in second language learners: Lessons from the report of the national literacy panel on language-minority children and youth. (pp. 1-17). New York: Routledge.

Babayiğit, S. \& Stainthorp, R. (2011). Modeling the relationships between cognitive-linguistic skills and literacy skills: New insights from a transparent orthography. Journal of Educational Psychology, 103, 169-189. doi: $10.1037 / \mathrm{a} 0021671$

Bedore, L.M. \& Peña, E.D. (2008). Assessment of bilingual children for identification of language impairment: Current findings and implications for practice. International Journal of Bilingual Education and Bilingualism, 11, 1-29. doi:10.2167/beb392.0

Bialystok, E. \& Martin, M.M. (2004). Attention and inhibition in bilingual children: Evidence from the dimensional change card sort task. Developmental Science, 7, 325-339. doi:10.1111/j.1467-7687.2004.00351.x

Bowey, J.A. (2005). Grammatical sensitivity: Its origins and potential contribution to early word reading skill. Journal of Experimental Child Psychology, 90, 318-343. doi: 10.1016/j.jecp.2004.12.002

Bowyer-Crane, C.A., Snowling, M., Duff, F.J., Fieldsend, E., Carroll, J.M., Miles, J. et al. (2008). Improving early language and literacy skills: Differential effects of an oral language versus a phonology with reading intervention. Journal of Child Psychology and Psychiatry, 49, 422-432. doi:10.1111/j.1469-7610.2007.01849.x

Burgoyne, K., Kelly, J.M., Whiteley, H.E. \& Spooner, A. (2009). The comprehension skills of children learning English as an additional language. British Journal of Educational Psychology, 79, 735-747. doi:10.1348/000709909X422530

Burgoyne, K., Whiteley, H.E. \& Hutchinson, J.M. (2010). The development of comprehension and reading-related skills in children learning English as an additional language and their monolingual, English-speaking peers. British Journal of Educational Psychology, 81, 344-354. doi:10.1348/000709910X504122

Cain, K. \& Oakhill, J. (2006). Assessment matters: Issues in the measurement of reading comprehension. British Journal of Educational Psychology, 76, 697-708. doi:10.1348/000709905X69807

Carlisle, J.F. (2004). Morphological processes that influence learning to read. In C.A. Stone, E. Silliman, B.J. Ehren \& K. Apel (Eds.), Handbook of language and literacy. (pp. 318-339). London: Guilford Press.

Carlisle, J.F. (2007). Fostering morphological processing, vocabulary development, and reading comprehension. In R.K. Wagner, A.E. Muse \& K.R. Tannenbaum (Eds.), Vocabulary acquisition. (pp. 78-103). London: Guilford Press.

Carlo, M.S., August, D., McLaughlin, B., Snow, C., Dressler, C., Lippman, D. et al. (2004). Closing the gap: Addressing the vocabulary needs of English-language learners in bilingual and mainstream classrooms. Reading Research Quarterly, 39, 188-215. doi:10.1598/RRQ.39.2.3

Carter, J.A., Lees, J.A., Murira, G.M., Gona, J., Neville, B.G.R. \& Newton, C.R.J.C. (2005). Issues in the development of cross-cultural assessments of speech and language for children. International Journal of Language \& Communication Disorders, 40, 385-401. doi:10.1080/13682820500057301

Catts, H.W., Fey, M., Zhang, X. \& Tomlin, B.J. (1999). Language basis of reading and reading disabilities: Evidence from a longitudinal investigation. Scientific Studies of Reading, 3, 331-361. doi:10.1207/s1532799Xssr0304_2

Chiappe, P., Glaeser, B. \& Ferko, D. (2007). Speech perception, vocabulary, and the development of reading skills in English among Korean- and English-speaking children. Journal of Educational Psychology, 99, 154-166. doi:10.1037/0022-0663.99.1.154

CILT (2011). CILT National centre for languages (operating as part of the CfBT education trust). Retrieved from http://www.cilt.org.uk/home/research_and_statistics/statistics/languages_in_the_population/other_related_sources. aspx

Clarke, P.J., Snowling, M.J., Truelove, E. \& Hulme, C. (2010). Ameliorating children's reading-comprehension difficulties. Psychological Science, 21, 1106-1116. doi:10.1177/0956797610375449

Cline, T. \& Shamsi, T. (2000). Language needs or special needs? The assessment of learning difficulties in literacy among children learning English as an additional language: A literature review. Retrieved from dera. ioe.ac.uk/4481/1/RR184.pdf

Cohen, J.D. (1988). Statistical power analysis for the behavioural sciences (2nd edn). Hillsdale, NJ: Erlbaum. 
Cohen, J.D. \& Cohen, P. (1983). Applied multiple regression/correlation analysis for the behavioural sciences (2nd edn). Hillsdale, NJ: Erlbaum.

Connor, H., Tyers, C., Modood, T. \& Hilage, J. (2004). Why the difference? A closer look at higher education minority ethnic students and graduates. Research Report, 552. Retrieved from https://www.education.gov.uk/ publications/standard/publicationDetail/Page1/RR552

Conti-Ramsden, G., Botting, N. \& Faragher, B. (2001). Psycholinguistic markers for specific language impairment. Journal of Child Psychology and Psychiatry, 42, 741-748. doi:10.1111/1469-7610.00770

Cummins, J. (1979). Linguistic interdependence and the educational development of bilingual children. Review of Educational Research, 49, 222-251. doi:10.3102/00346543049002222

Cummins, J. (1980). Psychological assessment of immigrant children. Journal of Multilingual and Multicultural Development, 1, 97-111. doi:10.1080/01434632.1980.9994005

Cutting, L.E. \& Scarborough, H.S. (2006). Prediction of reading comprehension: Relative contributions of word recognition, language proficiency, and other cognitive skills can depend on how comprehension is measured. Scientific Studies of Reading, 10, 277-299. doi:10.1207/s1532799Xssr1003_5

De Jong, P.F. \& van der Leij, A. (2002). Effects of phonological abilities and linguistic comprehension on the development of reading. Scientific Studies of Reading, 6, 51-77. doi:10.1207/S1532799XSSR0601_03

Devescovi, A. \& Cristina Caselli, M. (2007). Sentence repetition as a measure of early grammatical development in Italian. International Journal of Language \& Communication Disorders, 42, 187-208. doi:10.1080/13682820601030686

DfES (2005). Aiming high: Guidance on the assessment of pupils learning English as an additional language, DfES 2005 (ref/1469-2005doc-en). Retrieved from http://dera.ioe.ac.uk/6006/

DfES (2006). Ethnicity and education: The evidence on minority ethnic pupils aged 5-16 2006 ed. Retrieved from http://dera.ioe.ac.uk/6306/

Dockrell, J.E., Stuart, M. \& King, D. (2010). Supporting early oral language skills for English language learners in inner city preschool provision. British Journal of Educational Psychology, 80, 497-515. doi:10.1348/000709910X493080

Droop, M. \& Verhoeven, L. (2003). Language proficiency and reading ability in first- and second-language learners. Reading Research Quarterly, 38, 78-103. doi:10.1598/RRQ.38.1.4

Dunn, L.M., Dunn, D. \& National Foundation for Educational Research (2009). The British Picture Vocabulary Scale - 3 (3rd edn). London: GL Assessment.

Dunn, L.M., Dunn, L.M., Whetton, C. \& Burley, J. (1997). The British Picture Vocabulary Scale (2nd edn). London: NFER-Nelson.

Edmonds, M.S., Vaughn, S., Wexler, J., Reutebuch, C., Cable, A., Tackett, K.K. et al. (2009). A synthesis of reading interventions and effects on reading comprehension for older struggling readers. Review of Educational Research, 79, 262-300. doi:10.3102/0034654308325998

Ellis, N.C. (2005). At the interface: Dynamic interactions of explicit and implicit language knowledge. Studies in Second Language Acquisition, 27, 305-352. doi:10.1017/S027226310505014X

Erlam, R. (2006). Elicited imitation as a measure of L2 implicit knowledge: An empirical validation study. Applied Linguistics, 27, 464-491. doi:10.1093/applin/am1001

Field, A. (2005). Discovering statistics using SPSS for windows (2nd edn). London: Sage.

Flynn, N. \& Stainthorp, R. (2006). The learning and teaching of reading and writing. Chichester: Wiley-Blackwell.

Frederickson, N. \& Frith, U. (1998). Identifying dyslexia in bilingual children: A phonological approach with inner London Sylheti speakers. Dyslexia, 4, 119-131. doi:10.1002/(SICI)1099-0909(199809)4:3<119::AIDDYS112>3.0.CO;2-8

Geva, E. (2000). Issues in the assessment of reading disabilities in L2 children: Beliefs and research evidence. Dyslexia, 6, 13-28. doi:10.1002/(SICI)1099-0909(200001/03)6:1<13::AID-DYS155>3.0.CO;2-6

Geva, E. \& Farnia, F. (2011). Developmental changes in the nature of language proficiency and reading fluency paint a more complex view of reading comprehension in ELL and EL1. Reading and Writing (advanced online publication). doi:10.1007/s11145-011-9333-8

Ginsborg, J. (2006). The effects of socio-economic status on children's language acquisition and use. In J. Clegg \& J. Ginsborg (Eds.), Language and social disadvantage: Theory into practice. (pp. 9-27). Chichester: John Wiley and Sons.

Goldenberg, C., Reese, L. \& Rezaei, A. (2011). Contexts for language and literacy development among duallanguage learners. In A. Durgunoğlu \& C. Goldenberg (Eds.), Language and literacy development in bilingual settings. (pp. 3-25). New York: Guilford Press.

Gottardo, A. \& Mueller, J. (2009). Are first- and second-language factors related in predicting second-language reading comprehension? A study of Spanish-speaking children acquiring English as a second language from first to second grade. Journal of Educational Psychology, 101, 330-344. doi:10.1037/a0014320 
Gough, P.B. \& Tunmer, W.E. (1986). Decoding, reading and reading disability. Remedial and Special Education, 7, 6-10. doi:10.1177/074193258600700104

Hamers, J.F. \& Blanc, M.H.A. (2000). Bilinguality and bilingualism (2nd edn). Cambridge: University of Cambridge.

Hoover, W.A. \& Gough, P.B. (1990). The simple view of reading. Reading and Writing, 2, 127-160. doi:10.1007/ bf00401799

Hutchinson, J.M., Whiteley, H.E., Smith, C.D. \& Connors, L. (2003). The developmental progression of comprehension-related skills in children learning EAL. Journal of Research in Reading, 26, 19-32. doi:10.1111/14679817.261003

Jaccard, J., Turrisi, R. \& Wan, C.K. (1990). Interaction effects in multiple regression. London: Sage.

Keenan, J.M. \& Betjemann, R.S. (2006). Comprehending the Gray Oral Reading Test without reading it: Why comprehension tests should not include passage-independent items. Scientific Studies of Reading, 10, 363-380. doi:10.1207/s1532799Xssr1004_2

Kieffer, M.J. (2008). Catching up or falling behind? Initial English proficiency, concentrated poverty, and the reading growth of language minority learners in the United States. Journal of Educational Psychology, 100, 851-868. doi:10.1037/0022-()663.100.4.851

Kuhn, M.R. \& Stahl, S.A. (2003). Fluency: A review of developmental and remedial practices. Journal of Educational Psychology, 95, 3-21. doi:10.1037/0022-0663.95.1.3

Lervåg, A. \& Aukrust, V.G. (2010). Vocabulary knowledge is a critical determinant of the difference in reading comprehension growth between first and second language learners. Journal of Child Psychology and Psychiatry, 51, 612-620. doi:10.1111/j.1469-7610.2009.02185.x

Lesaux, N.K., Geva, E., Koda, K., Siegel, L. \& Shanahan, T. (2006). Development of literacy. In D. August \& T. Shanahan (Eds.), Developing literacy in second-language learners. (pp. 75-122). Hillsdale, NJ: Erlbaum.

Lesaux, N.K., Kieffer, M.J., Faller, S.E. \& Kelley, J.G. (2010). The effectiveness and ease of implementation of an academic vocabulary intervention for linguistically diverse students in urban middle schools. Reading Research Quarterly, 45, 196-228. doi:10.1598/RRQ.45.2.3

Lesaux, N.K., Lipka, O. \& Siegel, L. (2006). Investigating cognitive and linguistic abilities that influence the reading comprehension skills of children from diverse linguistic backgrounds. Reading and Writing, 19, 99-131. doi:10.1007/s11145-005-4713-6

Lesaux, N.K., Rupp, A.A. \& Siegel, L.S. (2007). Growth in reading skills of children from diverse linguistic backgrounds: Findings from a 5-year longitudinal study. Journal of Educational Psychology, 99, 821-834. doi:10.1037/0022-0663.99.4.821

Lesaux, N.K. \& Siegel, L.S. (2003). The development of reading in children who speak English as a second language. Developmental Psychology, 39, 1005-1019. doi:10.1037/0012-1649.39.6.1005

Lindsay, G., Dockrell, J., Desforges, M., Law, J. \& Peacey, N. (2010). Meeting the needs of children and young people with speech, language and communication difficulties. International Journal of Language \& Communication Disorders, 45, 448-460. doi:10.3109/13682820903165693

Lipka, O., Siegel, L.S. \& Vukovic, R. (2005). The literacy skills of English language learners in Canada. Learning Disabilities Research \& Practice, 20, 39-49. doi:10.1111/j.1540-5826.2005.00119.x

Lust, B., Flynn, S. \& Foley, C. (1996). What children know about what they say: Elicited imitation as a research method for assessing children's syntax. In D. McDaniel, C. McKee \& H.S. Cairns (Eds.), Methods of assessing children's syntax. (pp. 55-76). London: MIT Press.

Mahon, M. \& Crutchley, A. (2006). Performance of typically-developing school-age children with English as an additional language on the British Picture Vocabulary Scales II. Child Language Teaching and Therapy, 22, 333-351. doi:10.1191/0265659006ct311xx

McCardle, P., Scarborough, H.S. \& Catts, H.W. (2001). Predicting, explaining, and preventing children's reading difficulties. Learning Disabilities Research \& Practice, 16, 230-239. doi:10.1111/0938-8982.00023

McGregor, K.K. (2004). Developmental dependencies between lexical semantics and reading. In C.A. Stone, E. Silliman, B.J. Ehren \& K. Apel (Eds.), Handbook of language and literacy. (pp. 302-317). London: Guilford Press.

Melby-Lervåg, M. \& Lervåg, A. (2011). Cross-linguistic transfer of oral language, decoding, phonological awareness and reading comprehension: A meta-analysis of the correlational evidence. Journal of Research in Reading, 34, 114-135. doi:10.1111/j.1467-9817.2010.01477.x

Nagy, W.E. (2007). Metalinguistic awareness and the vocabulary-comprehension connection. In R.K. Wagner, A.E. Muse \& K.R. Tannenbaum (Eds.), Acquisition of vocabulary. (pp. 52-77). London: Guilford Press.

Nagy, W.E., Anderson, R.C. \& Herman, P.A. (1987). Learning word meanings from context during normal reading. American Educational Research Journal, 24, 237-270. doi:10.3102/00028312024002237 
Nakamoto, J., Lindsey, K. \& Manis, F. (2007). A longitudinal analysis of English language learners' word decoding and reading comprehension. Reading and Writing, 20, 691-719. doi:10.1007/s11145-006-9045-7

Nakamoto, J., Lindsey, K.A. \& Manis, F.R. (2008). A cross-linguistic investigation of English language learners' reading comprehension in English and Spanish. Scientific Studies of Reading, 12, 351-371. doi:10.1080/10888430802378526

Nation, K., Clarke, P., Marshall, C.M. \& Durand, M. (2004). Hidden language impairments in children: Parallels between poor reading comprehension and specific language impairments? Journal of Speech, Language, and Hearing Research, 47, 199-211. doi:10.1044/1092-4388(2004/017)

Nation, K., Cocksey, J., Taylor, J.S.H. \& Bishop, D.V.M. (2010). A longitudinal investigation of early reading and language skills in children with poor reading comprehension. Journal of Child Psychology and Psychiatry, 51, 1031-1039. doi:10.1111/j.1469-7610.2010.02254.x

Nation, K. \& Snowling, M.J. (2004). Beyond phonological skills: Broader language skills contribute to the development of reading. Journal of Research in Reading, 27, 342-356. doi:10.1111/j.1467-9817.2004.00238.x

Neale, M.D. (1997). Neale Analysis of Reading Ability (2nd revised British edn). London: GIL Assessment.

Oakhill, J. \& Cain, K. (2007). Introduction to comprehension development. In K. Cain \& J. Oakhill (Eds.), Children's comprehension problems in oral and written language. (pp. 3-40). London: Guilford Press.

Pearson, B. (2002). Narrative competence among monolingual and bilingual school children in Miami. In D.K. Oller \& R.E. Eilers (Eds.), Language and literacy in bilingual children. (pp. 135-174). Clevedon: Multilingual Matters.

Perfetti, C.A., Landi, N. \& Oakhill, J. (2005). The acquisition of reading comprehension skills. In M. Snowling \& C. Hulme (Eds.), The science of reading: A handbook. (pp. 227-247). Oxford: Blackwell.

Proctor, C.P., Carlo, M., August, D. \& Snow, C. (2005). Native Spanish-speaking children reading in English: Towards a model of comprehension. Journal of Educational Psychology, 97, 245-256. doi:10.1037/00220663.97.2.246

Proctor, C.P., Dalton, B., Uccelli, P., Biancarosa, G., Mo, E., Snow, C. et al. (2009). Improving comprehension online: Effects of deep vocabulary instruction with bilingual and monolingual fifth graders. Reading and Writing, 24, 517-544. doi:10.1007/s11145-009-9218-2

Ricketts, J., Nation, K. \& Bishop, D.V.M. (2007). Vocabulary is important for some, but not all reading skills. Scientific Studies of Reading, 11, 235-257. doi:10.1080/10888430701344306

Roberts, G., Mohammed, S.S. \& Vaughn, S. (2010). Reading achievement across three language groups: Growth estimates for overall reading and reading subskills obtained with the early childhood longitudinal survey. Journal of Educational Psychology, 102, 668-686. doi:10.1037/a0018983668

Rolstad, K., Mahoney, K. \& Glass, G.V. (2005). The big picture: A meta-analysis of program effectiveness research on English language learners. Educational Policy, 19, 572-594. doi:10.1177/0895904805278067

Romaine, S. (1989). Bilingualism. Oxford: Blackwell.

Scott, C.M. (2004). Syntactic contributions to literacy learning. In C.A. Stone, E. Silliman, J.B. Ehren \& K. Apel (Eds.), Handbook of language and literacy: Development and disorders. (pp. 340-362). London: Guilford Press.

Scott, C.M. (2009). A case for the sentence in reading comprehension. Language, Speech \& Hearing Services in Schools, 40, 184-191. doi:10.1044/0161-1461(2008/08-0042)

Seeff-Gabriel, B., Chiat, S. \& Dodd, B. (2010). Sentence imitation as a tool in identifying expressive morphosyntactic difficulties in children with severe speech difficulties. International Journal of Language \& Communication Disorders, 45, 691-702. doi:10.3109/13682820903509432

Semel, E., Wiig, E.H. \& Secord, W.A. (2006). Clinical evaluation of language fundamentals (4th UK edn). London: Pearson Assessment.

SFR (2010). Statistical First Release (SFR 09/2010): Schools, pupils and their characteristics (January 2010, provisional). Department for Education. Retrieved from http://www.dcsf.gov.uk/rsgateway/DB/SFR/s000925/ sfr09-2010.pdf

SFR (2011). Statistics First Release (SFR 31/2011): National curriculum assessment at Key Stage 2 in England 2010/11 (revised), 15th December 2011. Retrieved from http://www.education.gov.uk/rsgateway/DB/SFR/ s001047/index.shtml

SFR (2012). Statistical First Release: GCSE and equivalent attainment by pupil characteristics in England, 2010/11. Retrieved from http://www.education.gov.uk/rsgateway/DB/SFR/s001057/index.shtml

Spooner, A.L.R., Baddeley, A.D. \& Gathercole, S.E. (2004). Can reading accuracy and comprehension be separated in the Neale Analysis of Reading Ability? British Journal of Educational Psychology, 74, 187-204. doi:10.1348/000709904773839833

Stow, C. \& Dodd, B. (2003). Providing an equitable service to bilingual children in the UK: A review. International Journal of Language and Communication Disorders, 38, 351-377. doi: 10.1080/1368282031000156888 
Strand, S. (2008). Minority ethnic pupils in the longitudinal study of young people in England extension report on performance in public examinations at age 16. Department for Children, Schools and Families - RR029. London: Institute of Education, University of Warwick. Retrieved from http://www.dfes.gov.uk/research/data/ uploadfiles/DCSF-RR029.pdf

Strand, S. \& Demie, F. (2005). English language acquisition and educational attainment at the end of primary school. Educational Studies, 31, 275-291. doi:10.1080/03055690500236613

Stuart, M. (2004). Getting ready for reading: A follow-up study of inner city second language learners at the end of Key Stage 1. British Journal of Educational Psychology, 74, 15-36. doi:10.1348/000709904322848806

Tabachnick, B.G. \& Fidell, L.S. (2001). Using multivariate statistics (4th edn). London: Allyn and Bacon.

Thomas, W.P. \& Collier, V.P. (2002). A national study of school effectiveness for language minority students' long-term academic achievement. Retrieved from http://crede.berkeley.edu/research/crede/research/llaa/1.1_final.html

Thordardottir, E. (2010). Towards evidence-based practice in language intervention for bilingual children. Journal of Communication Disorders, 43, 523-537. doi:10.1016/j.jcomdis.2010.06.001

Tilstra, J., McMaster, K., Van den Broek, P., Kendeou, P. \& Rapp, D. (2009). Simple but complex: Components of the simple view of reading across grade levels. Journal of Research in Reading, 32, 383-401. doi:10.1111/ j.1467-9817.2009.01401.x

Van Gelderen, A., Schoonen, R., de Glopper, K., Hulstijn, J., Snellings, P., Simis, A. et al. (2003). Roles of linguistic knowledge, metacognitive knowledge and processing speed in L3, L2 and L1 reading comprehension. International Journal of Bilingualism, 7, 7-25. doi:10.1177/13670069030070010201

Verhoeven, L. (1990). Acquisition of reading in a second language. Reading Research Quarterly, 25, 90-114.

Verhoeven, L. (2000). Components in early second language reading and spelling. Scientific Studies of Reading, 4, 313-330. doi:10.1207/s1532799Xssr0404_4

Wagner, R.K., Muse, A.E. \& Tannenbaum, K.R. (2007). Promising avenues for better understanding implications of vocabulary development for reading comprehension. In R.K. Wagner, A.E. Muse \& K.R. Tannenbaum (Eds.), Vocabulary acquisition. (pp. 276-291). London: Guilford Press.

Walczyk, J. (1994). The development of verbal efficiency, metacognitive strategies, and their interplay. Educational Psychology Review, 6, 173-189. doi: 10.1007/BF02208972

Wechsler, D. (2003). Wechsler Intelligence Scale for Children (4th edn). San Antonio, TX: The Psychological Corporation.

Westby, C. (2004). A language perspective on executive functioning, metacognition, and self-regulation in reading. In C.A. Stone, E. Silliman, J.B. Ehren \& K. Apel (Eds.), Handbook of language and literacy. (pp. 398-427). London: Guilford Press.

Whetton, C. (1997). Technical supplement British Picture Vocabulary Scale II. Windsor: NFER-Nelson.

\section{Appendix}

Table A1. The comparison of the two cohorts on the test measures.

\begin{tabular}{|c|c|c|c|c|c|c|}
\hline \multirow[b]{2}{*}{ Measures } & \multicolumn{2}{|c|}{ Cohort $1(n=72)$} & \multicolumn{2}{|c|}{ Cohort $2(n=53)$} & \multirow[b]{2}{*}{$t(123)$} & \multirow[b]{2}{*}{$p$} \\
\hline & Mean & $S D$ & Mean & $S D$ & & \\
\hline Reading comprehension & 15.31 & 3.38 & 16.08 & 3.04 & -1.31 & .192 \\
\hline Word-reading accuracy & 145.81 & 5.81 & 147.17 & 3.41 & -1.65 & .102 \\
\hline Reading speed & 115.12 & 34.28 & 116.31 & 36.10 & -0.19 & .853 \\
\hline Listening comprehension & 9.19 & 3.65 & 8.68 & 3.09 & 0.83 & .408 \\
\hline Digit memory span & 12.79 & 2.39 & 13.28 & 2.55 & -1.10 & .272 \\
\hline Matrix reasoning & 18.04 & 4.26 & 18.32 & 4.03 & -0.37 & .712 \\
\hline Vocabulary & 91.43 & 18.22 & 90.34 & 16.83 & 0.34 & .733 \\
\hline Morphosyntactic skills & 56.35 & 14.13 & 54.09 & 12.74 & 0.92 & .360 \\
\hline
\end{tabular}

Note: Raw scores have been presented. 
Table A2. Partial correlation coefficients between the measures across the two language groups (L1 and L2) after controlling for age.

\begin{tabular}{lcccccccc}
\hline Measures & 1 & 2 & 3 & 4 & 5 & 6 & 7 & 8 \\
\hline 1. Reading comprehension & - & $.62 * *$ & $.50 * *$ & $.67 * *$ & .20 & .25 & $.56 * *$ & $.61 * *$ \\
2. Word-reading accuracy & .21 & - & $.69 * *$ & $.43 * *$ & .26 & .17 & $.40^{* *}$ & $.50 * *$ \\
3. Reading speed & .19 & $.48 * *$ & - & $.39 * *$ & $.31 *$ & .03 & $.41^{* *}$ & $.60 * *$ \\
4. Listening comprehension & $.56 * *$ & .15 & .16 & - & .06 & $.38 * *$ & $.60 * *$ & $.65 * *$ \\
5. Digit memory span & .28 & $.35 *$ & .23 & .18 & - & .01 & .14 & $.43 * *$ \\
6. Matrix reasoning & .17 & .24 & .33 & .32 & -.08 & - & $.39 *$ & .28 \\
7. Vocabulary & .32 & $.38 *$ & $.36 *$ & $.60 * *$ & .15 & $.49 * *$ & - & $.65 * *$ \\
8. Morphosyntactic skills & .31 & .33 & .13 & $.52 * *$ & .33 & $.35 *$ & $.61 * *$ & - \\
\hline
\end{tabular}

Note: Intercorrelations for the bilingual (L2) group are presented above the diagonal $(n=69)$, and intercorrelations for the monolingual (L1) group are presented below the diagonal $(n=56)$. After Bonferroni correction, the $p$ value was adjusted to .006 .

$* p<.01 ; * * p .001$.

Table A3. Proportion of L1 and L2 learners who scored one standard deviation below the mean on the measures of reading comprehension, listening comprehension, vocabulary and morphosyntactic skills.

\begin{tabular}{lcccc}
\hline & $\begin{array}{c}\text { Reading } \\
\text { comprehension }\end{array}$ & $\begin{array}{c}\text { Listening } \\
\text { comprehension }\end{array}$ & $\begin{array}{c}\text { Morphosyntactic } \\
\text { skills }\end{array}$ & Vocabulary \\
\hline L1 & $13 \%(n=7)$ & $20 \%(n=11)$ & $18 \%(n=10)$ & $16 \%(n=9)$ \\
L2 & $43 \%(n=30)$ & $51 \%(n=35)$ & $55 \%(n=38)$ & $57 \%(n=39)$ \\
$\chi^{2}(1, N=125)$ & $12.79 *$ & $11.54 *$ & $16.56^{*}$ & $19.71 *$ \\
\hline
\end{tabular}

Note: $\mathrm{L} 1=$ monolingual $(n=56) ; \mathrm{L} 2=$ bilingual $(n=69)$. Estimates were based on the L1 sample's means and standard deviations.

$* p<.001$.

Selma Babayiğit is a senior lecturer in the Department of Psychology at the University of the West of England (Bristol). She holds a BSc (Hons), an MSc (Child Development) and DPhil in Psychology from the University of London. Her research examines the role of a wide range of cognitive and linguistic factors that influence text comprehension and writing skills of monolingual and bilingual learners from diverse language backgrounds.

Received 11 May 2012; revised version received 29 May 2012.

Address for correspondence: Selma Babayiğit, Department of Psychology, University of the West of England, Coldharbour Lane, Bristol BS16 1QY, UK. E-mail: selma. babayigit@uwe.ac.uk 